\title{
Laccase kinetics of degradation and coupling reactions
}

\author{
Andrea Zille $^{\mathrm{a}}$, Florentina-Daniela Munteanu ${ }^{\mathrm{a}}$, Georg M. Gübitz ${ }^{\mathrm{b}}$, Artur Cavaco-Paulo ${ }^{\mathrm{a}, *}$ \\ ${ }^{\text {a }}$ University of Minho, Department of Textile Engineering, 4800-058 Guimarães, Portugal \\ ${ }^{\mathrm{b}}$ Graz University of Technology, Department of Environmental Biotechnology, $8010 \mathrm{Graz}$, Austria
}

Received 27 September 2004; received in revised form 17 January 2005; accepted 21 January 2005

Available online 17 February 2005

\begin{abstract}
The ability of Trametes villosa laccase to degrade an azo dye (methyl orange) and to catalyze the coupling reactions between the aromatic amines and catechol was studied. It was found that the apparent Michaelis-Menten constants obtained from amperometric measurements were comparable to the ones obtained in the oxygen consumption experiments $(8.20$ and $7.40 \mu \mathrm{M}$, respectively). From the measurements of the mediated and mediatorless currents of azo dye degradation and coupling reactions it was concluded that the addition of 1-hydroxybenzotriazole (HBT) as mediator considerably improves the catalytic efficiencies.

It can be concluded that the mediated coupling of the aromatic amine with catechol opens the perspectives of physical removal of these polluting chemicals from the nature and the usage of the laccase immobilized onto macro-electrodes in online systems with continuous monitoring of the enzyme activity.
\end{abstract}

(C) 2005 Elsevier B.V. All rights reserved.

Keywords: Kinetics; Laccase; Azo dye; Coupling; Aromatic amines

\section{Introduction}

Azo dyes, the largest chemical class of dyes with the greatest variety of colors, have been used extensively in the latest years for the textile dyeing and paper printing. The elimination of colored effluents in wastewater treatment systems is mainly based on expensive physical or chemical procedures such as adsorption, concentration, chemical transformation and incineration [1].

The extracellular ligninolytic enzyme system of white-rot fungi can degrade a wide variety of recalcitrant compounds, such as xenobiotics, lignin, and various types of dyes [2,3]. The major enzymes associated with the lignin-degrading ability of white-rot fungi are lignin peroxidase (EC 1.11.1.14) [4,5], manganese peroxidase (EC 1.11.1.13) [6-8] and laccase (EC 1.10.3.2) [9,10].

Laccases are multi-copper phenol oxidases, which reduces oxygen to water and simultaneously catalyze the oxidation

\footnotetext{
* Corresponding author. Tel.: +351253 510280; fax: +351 253510271.

E-mail address: artur@det.uminho.pt (A. Cavaco-Paulo).
}

of aromatic pollutants like anilines and phenols [11,12]. Several methods using laccase, immobilized laccase and laccase/mediator system have been developed for the treatment of the textile effluents [13-21]. This enzyme decolorizes some azo dyes without direct cleavage of the azo bond through a highly non-specific free radical mechanism, thereby avoiding the formation of toxic aromatic amines [22]. However, the substrate specificity of laccase limits the number of azo dyes that can be degraded [22-24].

Laccases can be also associated with an azo reductase, that under microaerophilic conditions can cleave a wider range of azo dyes into corresponding amines [25,26]. The Trametes villosa laccase is able to polymerize various substituted anilines through an oxidative oligomerization established by a nonenzymatic coupling reaction [27]. However, in order to enhance the degree of polymerization, catechol, a diphenolic compound, was added to the effluent [28]. The presence of catechol disfavors the aromatic amine self-coupling and enhances the coupling between catechol and the amines [29,30].

The copolymerization, between the oxidized anilines and catechol in the effluent, performed by simultaneously nonen- 
zymatic coupling and enzymatic polymerization showed products with low solubility. These kinds of reaction products were not observed when the anilines and catechol separately were reacted in presence of laccase in the same conditions [31]. The formation of the insoluble products brings the advantage that they can be removed from effluent in the form of a precipitate by further treatment processes.

In the present paper two approaches, the direct laccase decolorization of effluent and the coupling/polymerization laccase reaction in the azo reductase pretreated effluent have been compared on the basis of the kinetic parameters using an HBT/laccase system.

1-Hydroxybenzotriazole (HBT), the most researched mediator that is able to oxidize a variety of aromatic compounds, was used to broaden the range of azo dyes and to increase the decolorization or polymerization rates of laccase [10,32-34].

\section{Materials and methods}

\subsection{Chemicals}

The methyl orange dye (3-(4-dimethylamino-1-phenylazo) benzene sulfonic acid sodium salt) (see Fig. 1) was synthesized by the conventional method of coupling the diazonium salt of metanilic acid with either $N, N$-dimethyl$p$-phenylenediamine [35]. The minimum dye content was $90 \%$. The structures of the isolated dye, as sodium salts, were
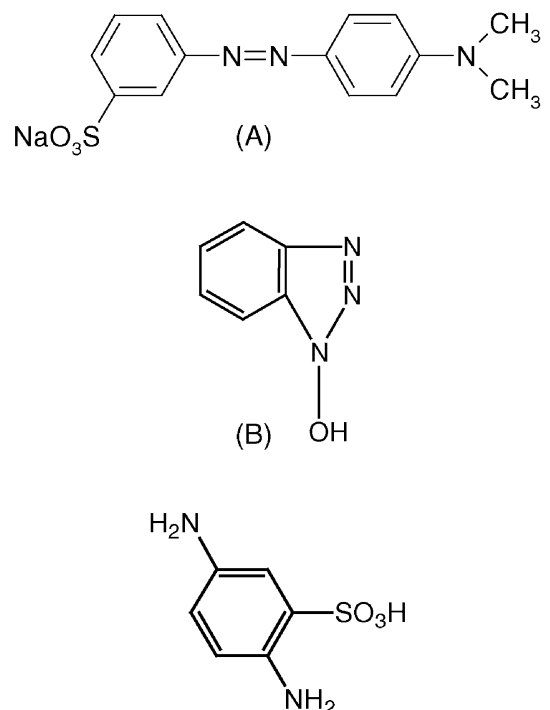

(C)

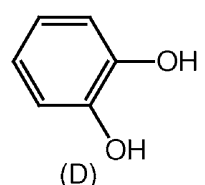

Fig. 1. Structure of the 3-(4-dimethylamino-1-phenylazo) benzene sulfonic acid sodium salt (A), 1-hydroxybenzotriazole (B), 2,5-diaminobenzene sulfonic acid (C), and catechol (D). confirmed by ${ }^{1} \mathrm{H}$ NMR spectroscopy in dymethylsulfoxide (DMSO).

1-Hydroxybenzotriazole and the salts were purchased from Sigma, St. Louis, MO. All chemicals were of high purity and used as received.

Laccase (EC 1.10.3.2) from T. villosa $(5.3 \mathrm{mg}$ protein $/ \mathrm{mL}$, $600 \mathrm{U} / \mathrm{mL}$ ) was kindly provided by Novo Nordisk, Denmark.

\subsection{Electrode preparation}

For the experiments with the laccase in solution was used as working electrode a glassy carbon electrode. Prior to the experiments the surface of the glassy carbon electrode was successively polished with $5,1,0.3$ and $0.05 \mu \mathrm{m}$ alumina polish (Buehler Ltd., USA) and then rinsed with $8 \mathrm{M}$ nitric acid and distilled water before use.

The laccase modified electrodes were prepared using rods of solid spectroscopic graphite (SGL Carbon, Werke Ringsdorff, Bonn, Germany, type RW001, 3.05 mm diameter). The graphite rods were first polished on wet fine-structured emery paper (grit size: P1200) and then additionally polished on paper to obtain a mirror-like surface. The electrode rods were carefully rinsed with deionized water and allowed to dry at room temperature. A $5 \mu \mathrm{L}$ aliquot of the enzyme solution was added to each of the polished ends of the graphite rods and the electrodes were then placed at $4{ }^{\circ} \mathrm{C}$ for $1 \mathrm{~h}$ in a glass beaker covered with sealing film, to allow the enzyme to adsorb slowly preventing rapid evaporation of the droplet of enzyme solution. The enzyme electrodes were then thoroughly rinsed with $0.1 \mathrm{M}$ sodium citrate buffer, $\mathrm{pH}$ 5.0, and if not immediately used, they were stored in the same buffer at $4{ }^{\circ} \mathrm{C}$. Weakly adsorbed laccase was desorbed before measurements, by rotating the electrode in buffer for at least $30 \mathrm{~min}$.

\subsection{Electrochemical experiments}

All the electrochemical experiments were performed using a Voltalab 30 Potentiostat (Radiometer Analytical, France), controlled by the Voltamaster 4 (version 5.6) electrochemical software. The working, counter and reference electrodes were respectively: glassy carbon electrode or the modified graphite electrode $\left(0.07 \mathrm{~cm}^{2}\right)$, coiled platinum wire $(23 \mathrm{~cm})$ and an $\mathrm{Ag} \mid \mathrm{AgCl}$ electrode filled with $3 \mathrm{M}$ $\mathrm{NaCl}$ (BAS, Bioanalytical Systems, West Lafayette, IN, USA). The supporting electrolyte used in the electrochemical cell was a solution of $0.1 \mathrm{M}$ sodium-citrate buffer $\mathrm{pH}$ 5.0. All solutions were deoxygenated through bubbling nitrogen for $20 \mathrm{~min}$ before measurements. All experiments were performed in bulk using amperometric detection (each experiment was repeated five times). The applied potential was $-50 \mathrm{mV}$ versus $\mathrm{Ag} \mid \mathrm{AgCl}$. The experiments were performed using a glassy carbon (laccase in solution) or a graphite electrode (laccase adsorbed onto the electrode surface). 
The ability of the laccase to decolorize the azo dye was investigated through addition of a freshly prepared dye solution to the electrolyte solution.

\subsection{Dissolved oxygen consumption rate}

Experiments were carried out in a Pyrex flask with a net volume of $250 \mathrm{~cm}^{3}$. A galvanic oxygen sensor (precision of $0.01 \mathrm{mg} / \mathrm{L}$ ) was used (WTW-InoLab Oxi level 2, Weilheim, Germany) to measure the dissolved oxygen concentration in the reaction medium.

To assure a constant temperature, the reactor was immersed in a thermostated water bath operating at $20^{\circ} \mathrm{C}$ with a precision of $\pm 0.1{ }^{\circ} \mathrm{C}$. The measurements (duplicates) were done under stirring, using a magnetic stirrer at $250 \mathrm{rpm}$. The monitoring of the degradation started after addition of $20 \mu \mathrm{L}$ laccase, and the concentration of the dissolved oxygen was monitored continuously for $15 \mathrm{~min}$. The registered response was corrected towards the response obtained for the blank samples (with just the buffer).

\subsection{Decolorization of the azo dye using laccase in the presence and in the absence of a mediator}

$2.5 \mathrm{~mL}$ azo dye solution $(10 \mathrm{mM})$ in $0.1 \mathrm{M}$ sodium-citrate buffer $\mathrm{pH} 5.0$ was incubated with $20 \mu \mathrm{L}$ of laccase and $0.5 \mathrm{~mL}$ of $0.1 \mathrm{M}$ sodium-citrate buffer $\mathrm{pH} 5.0$ in a standard cuvette at $25^{\circ} \mathrm{C}$. The absorbance was measured at different incubation times during the experiment and the percentage of effluent decolorization was calculated thereof.

In the case when the mediated degradation of the dye was investigated, then the buffer volume $(0.5 \mathrm{~mL})$ was replaced with $10 \mathrm{mM}$ buffered solution of 1-hydroxybenzotriazole (HBT).

\subsection{Coupling experiments}

Equimolar solutions of 2,5-diamino benzene sulfonic acid (DBSA) and catechol (10 mM; total volume $2.5 \mathrm{~mL}$ ) buffered with $0.1 \mathrm{M}$ sodium-citrate buffer $\mathrm{pH}$ 5.0, were incubated with $20 \mu \mathrm{L}$ of laccase and $0.5 \mathrm{~mL}$ of buffer in a standard stirred cuvette at $25^{\circ} \mathrm{C}$. In the case of experiments with mediator the buffer volume $(0.5 \mathrm{~mL})$ was replaced by $10 \mathrm{mM}$ buffered solution of HBT. Another experiment was performed with DBSA and laccase premixed solution and the catechol was added successively. The same experiments were performed with catechol and DBSA separately.

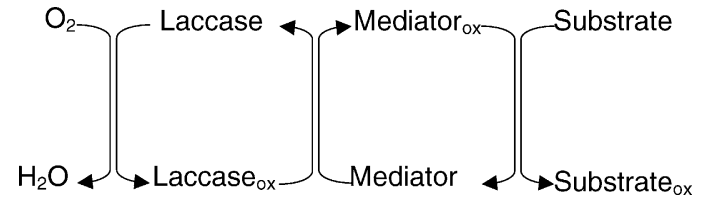

Fig. 2. Role of the mediator in the enzymatic activity.

\section{Results and discussion}

\subsection{Methyl orange degradation}

Laccase catalyzes the oxidation of organic substrates such as phenolic compounds by molecular oxygen in homogeneous solutions [36-40]. When laccase is adsorbed on graphite, bioelectrocatalytic reduction of oxygen occurs and is observed as a reduction current caused by direct (mediatorless) electron transfer (DET) from the electrode to the immobilized laccase and then further to molecular oxygen in solution. In the presence of soluble electron donors, laccase can be reduced in a mediated electron transfer (MET) mechanism (see Fig. 2). In this mechanism the electron donor (substrate) penetrates the active site of the enzyme where it is oxidized in a single electron oxidation step often producing an electrochemically active compound (possibly a radical) that in turn can be re-reduced at the electrode surface in a mediated electron transfer (MET) step.

The responses are dependent on the concentration of the azo dye in the solution of interest. At higher azo dye concentrations the current-concentration dependence gradually reached saturation (Fig. 3). The apparent Michaelis-Menten constants $\left(K_{\mathrm{m}}^{\mathrm{app}}\right)$ and maximal currents $\left(I_{\max }\right)$ have been calculated by fitting the variation of current-concentration dependencies of the analyzed compounds to the electrochemical Michaelis-Menten equation (Table 1) [41]. $K_{\mathrm{m}}^{\mathrm{app}}$ is an indicator of the affinity that an enzyme has for a given substrate.

The values of the $K_{\mathrm{m}}^{\mathrm{app}}$ obtained using the amperometric detection with laccase in solution and the monitoring of the oxygen consumption were found to be similar ( 8.2 and $7.4 \mu \mathrm{M}$, respectively).

The experiments with immobilized and free laccase are leading us to the conclusion that the immobilized laccase is less accessible than the free enzyme for interaction with the dye $[42,43]$. This fact is also confirmed by comparing the catalytic efficiencies of the oxidation reactions, values that for the adsorbed laccase were found to be about 300 times lower than for the system with laccase in solution.

Table 1

Results obtained for the oxidation of the methyl orange by laccase (each experiment was repeated five times)

\begin{tabular}{lcc}
\hline & $I_{\max }(\mu \mathrm{A}) \pm$ S.D. & $K_{\mathrm{m}}^{\text {app }}(\mu \mathrm{M}) \pm \mathrm{S} . \mathrm{D}$. \\
\hline Azo dye and laccase immobilized & $0.793 \pm 0.002$ & $31.497 \pm 0.075$ \\
Azo dye and laccase immobilized + HBT & $1.510 \pm 0.009$ & $0.699 \pm 0.004$ \\
Azo dye and laccase in solution & $29.442 \pm 0.187$ & $8.206^{\mathrm{a}} \pm 0.052$ \\
Azo dye and laccase in solution + HBT & $1.781 \pm 0.012$ & $0.377 \pm 0.003$ \\
\hline
\end{tabular}

a Value comparable with the $K_{\mathrm{m}}^{\mathrm{app}}(7.40 \mu \mathrm{M})$ obtained in the oxygen consumption experiments. 


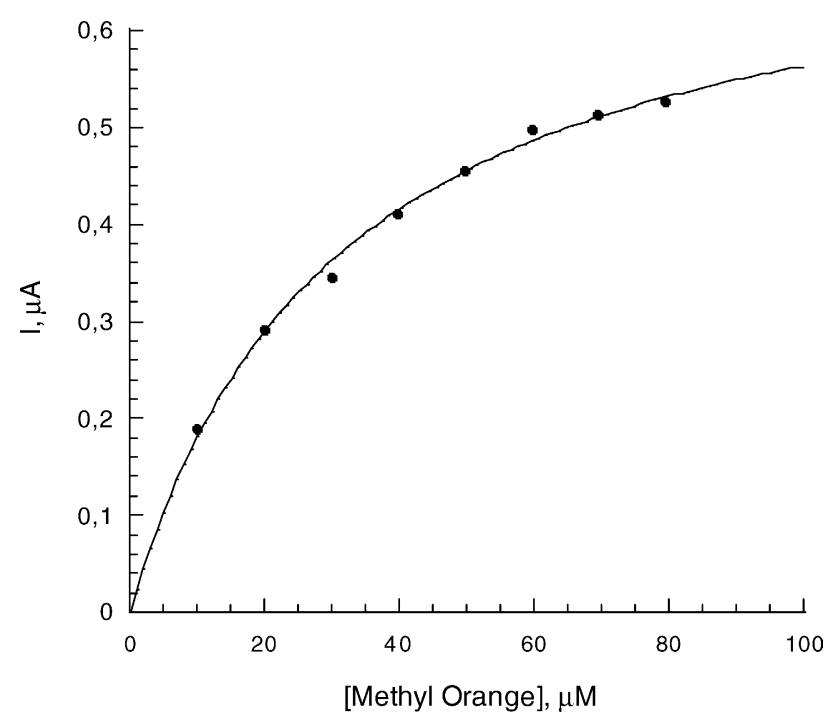

Fig. 3. Calibration graph for methyl orange obtained with a laccase modified graphite electrode in $0.1 \mathrm{M}$ citrate buffer $\mathrm{pH} 5.0$, at $-50 \mathrm{mV}$ vs. $\mathrm{Ag} \mid \mathrm{AgCl}$ electrode filled with $3 \mathrm{M} \mathrm{NaCl}$.

The presence of HBT in the system led to lower $K_{\mathrm{m}}^{\mathrm{app}}$ (between 20 and 50 times lower) than in the mediatorless system. The kinetics of mediated laccase catalyzed reactions is firstly affected by the affinity between enzyme and the mediator. An estimation of this influence can be done by amperometric measurements in terms of $I_{\max } / K_{\mathrm{m}}^{\text {app }}$ ratio. Lower $K_{\mathrm{m}}^{\text {app }}$ values at similar catalytic currents involved higher effectiveness of the enzyme at lower mediator concentrations.

From the results obtained with free laccase in solution and with laccase adsorbed onto the graphite electrodes it can be concluded that the best system is the one with laccase in solution because it shows a higher catalytic efficiency and a more narrow dynamic range as a consequence of a higher $I_{\max }$ and a lower $K_{\mathrm{m}}^{\mathrm{app}}$ value.

It is interesting to note that the presence of the HBT in this system led to a 15 times lower $I_{\max }$ value than the one obtained for the mediatorless system. This result might be explained considering that an electrode fouling might occur due to the initial step that is the oxidation of $\mathrm{HBT}$ to $\mathrm{HBT}^{\bullet+}$ by laccase, followed by the deprotonation of $\mathrm{HBT}^{\bullet+}$ with formation of a nitroxyl radical. The latter eventually abstracts the benzylic hydrogen from the substrate, thereby giving rise to the aldehyde and producing HBT back [34].

\subsection{Coupling experiments}

The feasibility of oxidative coupling between xenobiotics in the presence of oxidoreductive enzymes for the remediation of environmental pollution has been described by various researchers [44-46].

In our studies we used catechol as coupler to enhance the possibility of removal of the aromatic amines formed during the azo dye degradation. At the same time DBSA was chosen since it is one of the most studied precursors of the coupling reactions [29].

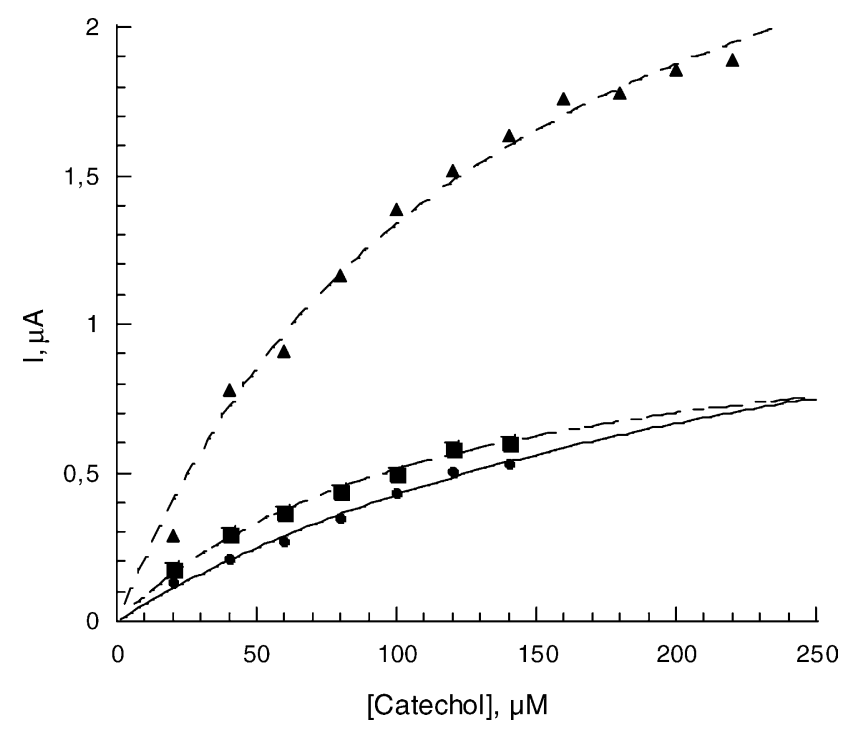

Fig. 4. Calibration graph obtained for oxidation of catechol by laccase in presence of HBT: $(\bullet)$ catechol premixed with DBSA, (ם) catechol alone, $(\Lambda)$ catechol added after previous addition of DBSA to the system, in $0.1 \mathrm{M}$ citrate buffer $\mathrm{pH} 5.0$, at $-50 \mathrm{mV}$ vs. $\mathrm{Ag} \mid \mathrm{AgCl}$ electrode filled with $3 \mathrm{M}$ $\mathrm{NaCl}$.

It was observed that in presence of DBSA the addition of catechol or of laccase to the system gave no change in the current, even if HBT (as mediator) was added to the solution. The absence of a measurable signal at the used concentration of DBSA permitted us to run further experiments in order to study the unmediated and mediated coupling of the catechol with DBSA in presence of laccase.

Firstly the response of the catechol oxidation by laccase was monitored in the absence and in the presence of $100 \mu \mathrm{M}$ HBT. Since the response of the sensor is proportional to the concentration of the catechol in solution, then if the catechol is consumed in the coupling reaction with DBSA this will be observed as decay in the current (Fig. 4).

When the coupling reaction was studied in the absence of HBT the current measured was due to the oxidation of catechol by laccase (figure not shown). In the coupling reactions it could be observed that signal measured due to the addition of catechol was lower if DBSA was present into the electrolyte solution. The same low response was observed if the catechol was added after previous mixing with DBSA (equimolar ratio). As can be seen from Table 2, for this case the values of $I_{\max }$ are decreased in both cases when DBSA is present in the electrolyte solution, and, moreover an increase in the values of $K_{\mathrm{m}}^{\mathrm{app}}$ is observed leading us to the conclusion that a competitive reaction (coupling of the catechol with DBSA) might take place.

In the presence of HBT as mediator it was also observed a diminution in the current registered for the case when the catechol and DBSA were mixed (equimolecular ratio) prior to the addition to the electrolyte solution (marked with in Fig. 4) in respect to the response obtained when the catechol addition was made just in the presence of laccase and of the HBT (marked with $\mathbf{q}$ in Fig. 4). Surprisingly when the 
Table 2

Results obtained for the coupling reaction of the DBSA with catechol (each experiment was repeated five times)

\begin{tabular}{|c|c|c|c|}
\hline & $I_{\max }(\mu \mathrm{A}) \pm$ S.D. & $K_{\mathrm{m}}^{\mathrm{app}}(\mu \mathrm{M}) \pm \mathrm{S} . \mathrm{D}$. & $I_{\max } / K_{\mathrm{m}}^{\mathrm{app}}\left(\mu \mathrm{A} \mu \mathrm{M}^{-1}\right) \pm$ R.S. D. \\
\hline Catechol and laccase & $2.399 \pm 0.014$ & $146.970 \pm 0.884$ & $0.0163 \pm 0.008$ \\
\hline DBSA and laccase & n.d. ${ }^{\mathrm{a}}$ & n.d. & n.d. \\
\hline DBSA and catechol & n.d. & n.d. & n.d. \\
\hline DBSA/laccase premixed and catechol & $1.741 \pm 0.011$ & $174.750 \pm 1.091$ & $0.0099 \pm 0.002$ \\
\hline DBSA/catechol premixed and laccase & $1.935 \pm 0.017$ & $226.110 \pm 1.988$ & $0.0086 \pm 0.001$ \\
\hline Catechol and laccase $+\mathrm{HBT}$ & $1.535 \pm 0.011$ & $260.700 \pm 1.841$ & $0.0059 \pm 0.007$ \\
\hline DBSA and laccase $+\mathrm{HBT}$ & n.d. & n.d. & n.d. \\
\hline DBSA and catechol + HBT & n.d. & n.d. & n.d. \\
\hline DBSA/laccase premixed and catechol + HBT & $3.128 \pm 0.006$ & $133.470 \pm 0.274$ & $0.0234 \pm 0.002$ \\
\hline DBSA/catechol premixed and laccase $+\mathrm{HBT}$ & $1.113 \pm 0.004$ & $117.630 \pm 0.498$ & $0.0094 \pm 0.005$ \\
\hline
\end{tabular}

DBSA in presence of catechol or in the presence of laccase gave no change in the current even in the presence of HBT.

${ }^{\mathrm{a}}$ n.d.: not detectable.

addition of the catechol to the system was made after addition of the HBT and DBSA it was observed that the registered currents for catechol (marked with $\boldsymbol{\Delta}$ in Fig. 4) are higher than in the absence of DBSA (amplification factor of 2).

In the premixed solution of DBSA and catechol it might be formed a coupling product before the addition of laccase to the bulk solution and the presences of HBT favored the copolymerization reaction $[29,47]$. From Table 2 it can be seen that the values obtained for the $K_{\mathrm{m}}^{\mathrm{app}}$ for the premixed solutions of catechol and DBSA, are decreasing when the reaction occurs in presence of HBT.

At the same time when the catechol were added after addition of laccase to the solution of DBSA, the values for $K_{\mathrm{m}}^{\mathrm{app}}$ shows the same tendency to decrease in presence of HBT. However, the best coupling system seems to be the premixed solution of DBSA and catechol in the presence of HBT.

A full understanding of the interaction between catechol and DBSA especially in the presence of HBT and its implications on the Michaelis-Menten kinetics remain to be elucidated.

\section{Conclusion}

With the addition of the HBT as a mediator it was possible to improve the degradation of the methyl orange using laccase. Indeed the results obtained with the laccase in solution seem to be better than the immobilized laccase, but the differences are not so dramatic. Beside, the good results obtained when the laccase is adsorbed onto the electrode surface gives us excellent promises for usage of these systems in online monitoring of the enzyme activity.

The present study also reveals the possibility of removal of the aromatic amines eventually obtained in the degradation of the azo dyes processes by coupling reactions with catechol, also enhanced by the presence of HBT in the system.

In our opinion the main advantages of these reactions are brought by the fact that if this method is used for removal of the aromatic amines from the polluted water or soil then is not necessary any further addition of the catechol to the system, since is already existent in the humic substances of the soil.

\section{Acknowledgments}

The authors would like to thank the Portuguese Foundation of Science and Technology (FCT) for providing the grants to Andrea Zille (SFRH/BD/4720/2001) and Florentina-Daniela Munteanu (SFRH/BPD/16674/2004).

\section{References}

[1] M.T. Moreira, G. Feijoo, J.M. Lema, Biotechnol. Lett. 22 (2000) 1499-1503.

[2] T.K. Kirk, R. Farell, Ann. Rev. Microbiol. 41 (1987) 465-505.

[3] A. Paszczynski, R.L. Crawford, Biotechnol. Prog. 11 (1995) 368-379.

[4] D. Moldes, S. Rodriguez Couto, C. Cameselle, M.A. Sanroman, Chemosphere 51 (2003) 295-303.

[5] S. Macarena, L.L. Fernando, V. Monica, V. Rafael, G. Bernardo, FEMS Microbiol. Lett. 242 (2005) 37-44.

[6] C. Novotny, K. Svobodova, P. Erbanova, T. Cajthaml, A. Kasinath, E. Lang, V. Sasek, Soil Biol. Biochem. 36 (2004) 1545-1551.

[7] A. Lisov, A. Leontievsky, L. Golovleva, C. Evans, J. Mol. Catal. B: Enzym. 31 (2004) 1-8.

[8] P.P. McCue, K. Shetty, Process Biochem. 40 (2005) 1143-1150.

[9] R. Vicuna, Mol. Biotechnol. 14 (2000) 173-176.

[10] C. Sigoillot, S. Camarero, T. Vidal, E. Record, M. Asther, M. PerezBoada, M.J. Martinez, J.-C. Sigoillot, M. Asther, J.F. Colom, A.T. Martinez, J. Biotechnol. 115 (2005) 333-343.

[11] R. Bourbonnais, M.G. Paice, B. Freiermuth, E. Bodie, S. Borneman, Appl. Environ. Microbiol. 12 (1997) 4627-4632.

[12] A. Robles, R. Lucas, A.G. De Cienfuegos, A. Galvez, Enzyme Microb. Technol. 26 (2000) 484-490.

[13] N. Kirby, R. Marchant, G. McMullan, FEMS Microbiol. Lett. 188 (2000) 93-96.

[14] C. Novotny, K. Svobodova, A. Kasinath, P. Erbanova, Int. Biodeterior. Biodegr. 54 (2004) 215-223.

[15] P. Blanquez, N. Casas, X. Font, X. Gabarrell, M. Sarra, G. Caminal, T. Vicent, Water Res. 38 (2004) 2166-2172.

[16] C. Maximo, M. Costa-Ferreira, Process Biochem. 39 (2004) $1475-1479$

[17] D. Wesenberg, I. Kyriakides, S.N. Agathos, Biotechnol. Adv. 22 (2003) 161-187. 
[18] M.A.M. Martins, N. Lima, A.J.D. Silvestre, M.J. Queiroz, Chemosphere 52 (2003) 967-973.

[19] P. Peralta-Zamora, C.M. Pereira, E.R.L. Tiburtius, S.G. Moraes, M.A. Rosa, R.C. Minussi, N. Duran, Appl. Catal. B: Environ. 42 (2003) 131-144.

[20] G.M.B. Soares, M.T.P.E. Amorim, R. Hrdina, M. Costa-Ferreira, Process Biochem. 37 (2002) 581-587.

[21] T. Robinson, B. Chandran, P. Nigam, Enzyme Microbial Technol. 29 (2001) 575-579.

[22] M. Chivukula, V. Renganathan, Appl. Environ. Microbiol. 61 (1995) 4374-4377.

[23] K.T. Chung, C.E. Cerniglia, Mutat. Res. 277 (1992).

[24] K.T. Chung, J.S.E. Stevens, Environ. Toxicol. Chem. 12 (1993) 2121-2132.

[25] P.A. Ramalho, H. Scholze, M.H. Cardoso, M.T. Ramalho, A.M. Oliveira-Campos, Enzyme Microb. Technol. 31 (2002) 848854.

[26] T. Hoff, S.Y. Liu, J.M. Bollag, Appl. Environ. Microb. 49 (1985) 1040-1045.

[27] A.V. Karamyshev, S.V. Shleev, O.V. Koroleva, A.I. Yaropolov, I.Y. Sakharov, Enzyme Microb. Technol. 33 (2003) 556-564.

[28] N. Aktas, A. Tanyolac, J. Mol. Catal. B: Enzym. 22 (2003) 61-69.

[29] J.S. Anderson, J. Soc. Dyers Colour. 116 (2000) 193-196.

[30] R. Pilz, E. Hammer, F. Schauer, U. Kragl, Appl. Microbiol. Biotechnol. 60 (2003) 708-712.

[31] S. Thiele, E. Fernendes, J.M. Bollag, J. Environ. Qual. 31 (2002) 437-444.
[32] E. Srebotnik, K.E. Hammel, J. Biotechnol. 81 (2000) 179-188.

[33] R. Bourbonnais, D. Leech, M.G. Paice, Biochim. Biophys. Acta: Gen. Subjects 1379 (1998) 381-390.

[34] G. Cantarella, C. Galli, P. Gentili, J. Mol. Catal. B: Enzym. 22 (2003) 135-144.

[35] B.S. Furniss, A.J. Hannaford, P.W.G. Smith, A.R. Tatchell, Vogel's Textbook of Practical Organic Chemistry, 5th ed., Longman Group UK Ltd., Harlow, Essex, 1989, 951 pp.

[36] A. Leonowicz, N.-S. Cho, J. Luterek, A. Wilkolazka, M. WojtasWasilewska, A. Matuszewska, M. Hofrichter, J.W.D. Rogalski, J. Basic Microbiol. 41 (2001) 183-225.

[37] K.-S. Shin, J. Microbiol. 42 (2004) 37-41.

[38] S. Rodriguez Couto, M.A. Sanroman, D. Hofer, G.M. Gubitz, Bioresour. Technol. 95 (2004) 67-72.

[39] P. Baldrian, Appl. Microbiol. Biotechnol. 63 (2004) 560-563.

[40] C. Cameselle, M. Pazos, M. Lorenzo, M.A. Sanrom, Biotechnol. Lett. 25 (2003) 603-606.

[41] R. Shu, G.S. Wilson, Anal. Chem. 48 (1976) 1679-1686.

[42] A. Emine, T. Leman, Appl. Biochem. Biotechnol. 50 (1995) 291-303.

[43] A. Zille, T. Tzanov, G.M. Gubitz, A. Cavaco-Paulo, Biotechnol. Lett. 25 (2003) 1473-1477.

[44] J.-M. Bollag, C. Myers, Sci. Total Environ. 117/118 (1992) 357-366.

[45] A.M. Klibanov, T.M. Tu, K.P. Scott, Science 221 (1983) 259-261.

[46] K.E. Simmons, R.D. Minard, J.-M. Bollag, Environ. Sci. Technol. 23 (1989) 115-121.

[47] K.A. Thorn, Environ. Sci. Technol. 30 (1996) 2764-2775. 